\title{
In Vitro Sugar Accumulation in Juice Sacs of 'Shiranuhi' Mandarin
}

\author{
Doo-Gyung Moon*, Sung-Gap Han, Jae-Ho Joa, Chun-Hwan Kim, and Ki-Cheol Seong \\ National Institute of Horticultural \& Herbal Science, Rural Development Administration, Jeju 690-150, Korea
}

\begin{abstract}
To further our understanding of sugar accumulation in 'Shiranuhi' mandarin $[(C$. unshiu $\times$ C. sinensis $)$ $\times C$. reticulate], we investigated the patterns of sugar uptake in juice sacs exposed to different concentrations of sucrose, fructose and glucose in vitro. Data was also collected on the change in weight and shape of the in vitro juice sacs over time. Soluble solids content, sugar content and acidity content were highest at $20 \%$ sucrose, fructose and glucose solution content; while fructose content was highest at 5\% sucrose concentration. Furthermore, the juice sac's fresh weight was highest at 5\% sucrose and lowest at $20 \%$ fructose content. The shape of the juice sacs also differed in different sugar concentration and type. Overall, sucrose, fructose and glucose content in juice sacs increased with the sugar concentration. These results suggest that sugar translocation into juice sacs is actively induced by high sugar concentration in the medium. Thus, it can be concluded that sugar and acid accumulation in juice sacs increased with sugar concentration in vitro culture.
\end{abstract}

Additional key words: citrus, in vitro culture, sugar content

\section{Introduction}

Juice sacs are initiated at about bloom, appears at first as dome shaped protrusions from the segment membrane into the segments (Nii and Coombe, 1988), after which cell division followed by cell elongation and maturation are observed as in grapefruit (Burns et al., 1992). It is distributed in a radial direction in the segment and appears to elongate with maturity. The number of juice sacs in the segment is determined by fruit size coupled with an increase in juice and sugar content. Juice sacs appear as elongated, mostly spindle-shaped from a stalk implanted in the periphery of the segment toward the central axis with sucrose and carotenoid accumulation in mature citrus fruit (Spiegel-Roy and Goldschmidt, 1996).

Sucrose is commonly the dominant sugar component in citrus fruit and sucrose as a translocated sugar from leaves is cleaved in dorsal and septal vascular bundles of the citrus fruit, which are terminal unloading sites before the sugars enter the juice sacs (Lowell et al., 1989; Tomlinson et al., 1991). Sucrose concentration in the juice may be regulated by both synthetic sucrose synthase and acid invertase activities in the juice sacs (Kubo et al., 2001). Vacuolar sugars are the major form of carbohydrate that supply energy to mature juice sac cells.

Sugar accumulation by in vitro cultured juice sac vesicles has been reported in satsuma mandarin (Mukai et al., 2000, 2001) and in grapefruit (Huberman et al., 2005). However, the response of the 'Shiranuhi' mandarin juice sacs to different sugar concentrations in vitro has not been reported.

'Shiranuhi' mandarin, a hybrid between Kiyomi ('Miyagawa' satsuma mandarin $\times$ 'Trovita' orange) and ponkan (Saunt, $2000)$ is generally known to have higher SS (12.5-15.8 ${ }^{\circ}$ Brix) and acid (0.8-1.2\%) at harvest (Matsumoto, 2001; Moon et al., 2008). It is a premium fruit with high quality among citrus variety in the domestic market. To further our understanding of sugar accumulation in 'Shiranuhi' mandarin [(C. unshiu $\times C$. sinensis $) \times C$. reticulate], we investigated the patterns of sugar uptake in juice sacs exposed to different concentrations of sucrose, fructose and glucose in vitro. Here we report sucrose, fructose, and glucose uptake patterns; and changes in acidity, fresh weight and juice sac shape in 'Shiranuhi' mandarin juice sacs cultured in vitro.

\section{Material and Methods}

\section{Plant Materials}

Samples were obtained from young fruit (50 days after

\footnotetext{
*Corresponding author: dgmoon@korea.kr

※ Received 18 June 2012; Revised 6 December 2012; Accepted 15 February 2013. We would like to thank Dr. Laban K. Rutto at the Virginia State University School of Agriculture for editing this paper.
} 

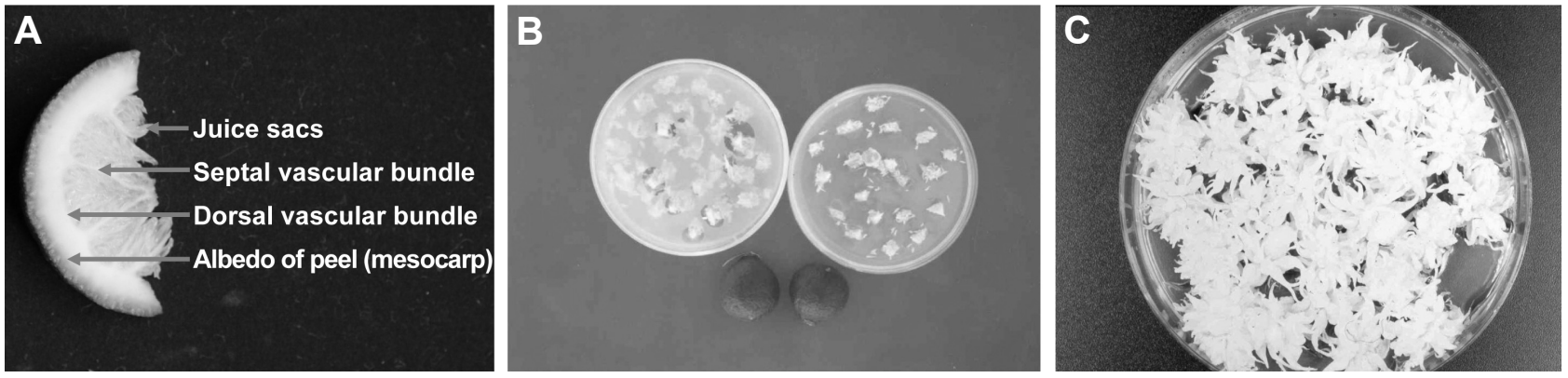

Fig. 1. Schematic representation of sampling and culture of 'Shiranuhi' $[($ C. unshiu $\times$ C. sinensis $) \times$ C. reticulate $]$ mandarin vesicles. (A) Explants attached to the mesocarp were excised from young fruit (50 days after anthesis). (B) Explants cultured in MS media supplemented with $1 \mathrm{mg} \cdot \mathrm{L}^{-1} \mathrm{BA}, 1 \%$ agar, and 5,10 , and $20 \%$ of sucrose, fructose and glucose, respectively, were incubated in the dark at $25^{\circ} \mathrm{C}$. (C) Explants harvested after 3 months.

anthesis) which were from ten-year-old 'Shiranuhi' mandarin $[(C$. unshiu $\times$ C. sinensis $) \times C$. reticulate $]$ trees grafted on trifoliate orange rootstocks. Trees were grown in non-heated plastic houses for 5 years in Jeju, South Korea. The fruits were surface sterilized by soaking for $10 \mathrm{~min}$ in $70 \%$ ethanol, followed by $30 \mathrm{~min}$ in $1 \%(\mathrm{w} / \mathrm{v}) \mathrm{NaOCl}$ before rinsing in sterile water. Sections of the mesocarp from the inner walls of the fruit segments along with the attached juice sac primordia were excised. Mid section of the fruit were inserted in plastic petri dishes with the endocarp side up such that the juice sacs were not in contact with the media (Fig. 1). The dishes, filled with $10 \mathrm{~mL}$ of Murashige and Skoog (1962) media supplemented with $1 \mathrm{mg} \cdot \mathrm{L}^{-1} \mathrm{BA}$ and $1 \%(\mathrm{w} / \mathrm{v})$ agar and 5, 10, and 20\% sucrose, fructose and glucose, respectively, were incubated in the dark at $25^{\circ} \mathrm{C}$. The $\mathrm{pH}$ of the media was adjusted to 5.6-5.8 and autoclaved for $15 \mathrm{~min}$ at $121^{\circ} \mathrm{C}$ before use, and a minimum of 18-25 juice sac primordia were placed in each dish. The explants were harvested after 3 months and the juice sac growth and sugar content were determined.

\section{Juice Extraction and Analysis}

The juice sacs were carefully detached from mesocarp with a pair of forceps and fresh weight was determined by weighing. Juice samples were manually extracted from the juice sacs by hand expressing through cheesecloth followed by filtration, and storage at $-20^{\circ} \mathrm{C}$ pending analysis. After thawing to room temperature, the juice soluble solids content (SSC) was measured using a digital refractometer (PR-1, Atago, Tokyo, Japan), while acidity was determined by titrating $1 \mathrm{~mL}$ of juice with $0.1 \mathrm{~N} \mathrm{NaOH}$ to $\mathrm{pH} 7.0$ using phenolphthalein as an indicator, before converting titratable acidity to citric acid equivalent.

\section{Free Sugars Analysis}

Sugar content was measured using a Bio-LC (Dionex,

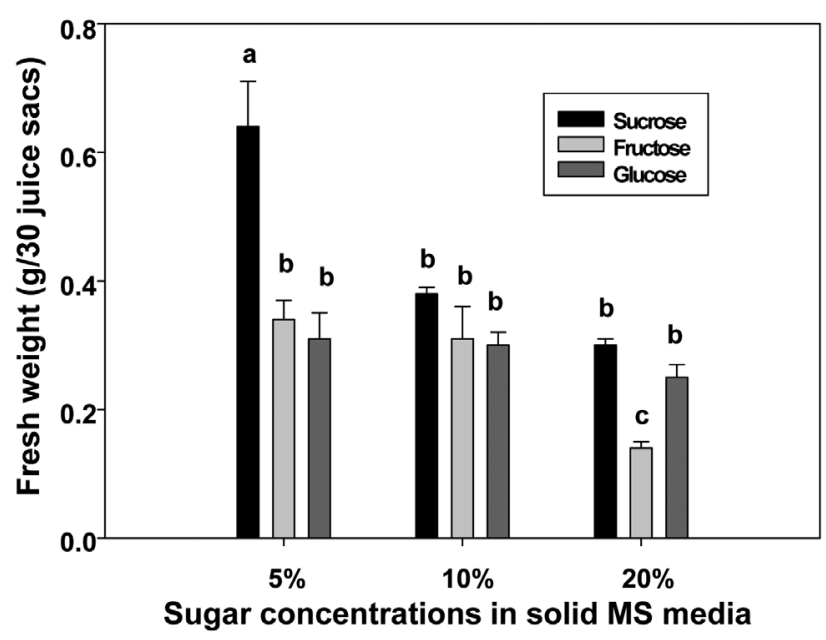

Fig. 2. Fresh weight of 'Shiranuhi' [(C. unshiu $\times$ C. sinensis $)$ $\times$ C. reticulate] mandarin juice sacs (30 units) cultured in vitro in MS media supplemented with $1 \mathrm{mg} \cdot \mathrm{L}^{-1} \mathrm{BA}, 1 \%$ agar, and 5,10 , and $20 \%$ of sucrose, fructose and glucose, respectively. Bars represent standard error ( $n=30$ juice sacs) and columns with the same letter within treatment are not significantly different at $P=0.05$.

DX-500) system. Samples were diluted $(\times 1000)$ with pure water and filtered through a Millipore filter $(0.45 \mu \mathrm{m})$ before analysis. The detector was equipped with electrochemical, INT amperometry, and Bio-LC conditions during analysis of free sugars (sucrose, fructose, and glucose) and the results were as follows: the column was CarbopacTM PA1, the mobile phase was $100 \mathrm{mM} \mathrm{NaOH}$. Sample volume injected was $0.5 \mu \mathrm{L}$ and the flow rate was $0.6 \mu \mathrm{L} \cdot \mathrm{min}^{-1}$ with column temperature maintained at $28^{\circ} \mathrm{C}$.

\section{Results and Discussion}

\section{Fresh Weight and Shape of the Juice Sacs}

The fresh weight of juice sacs cultured in MS media differed with sugar concentration and type (Fig. 2). Juice sac's fresh weigh was significantly higher in media amended 

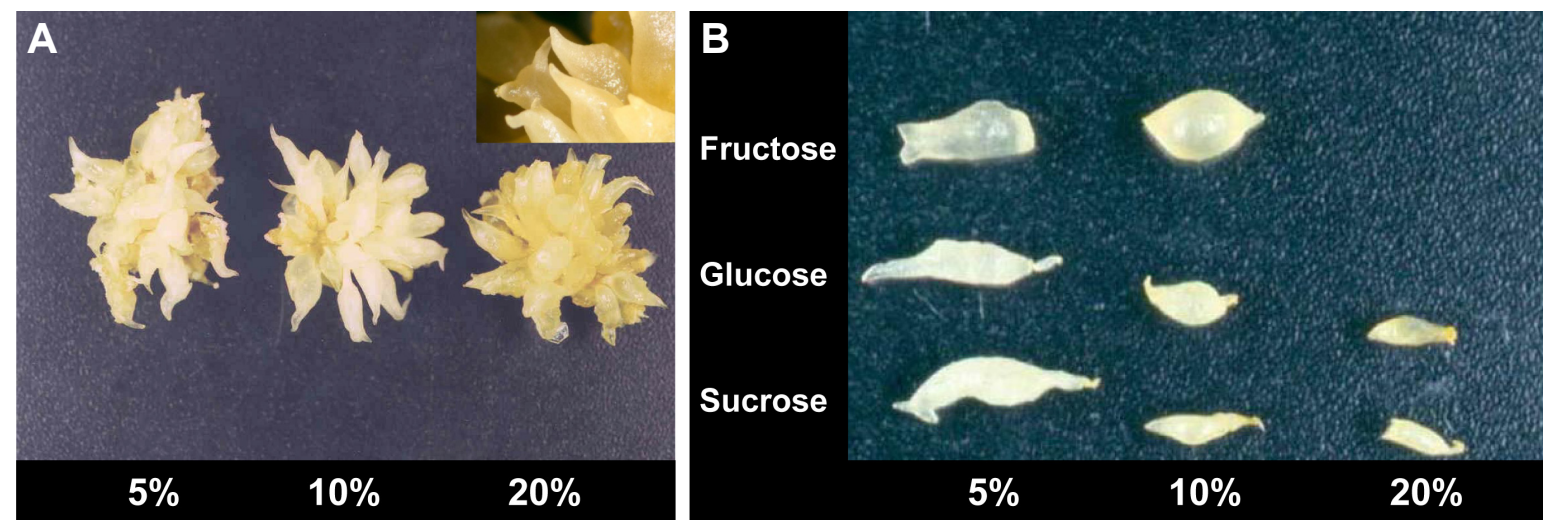

Fig. 3. Pictorial representations of 'Shiranuhi' $[($ C. unshiu $\times$ C. sinensis $) \times$ C. reticulate $]$ mandarin juice sac shape and color following in vitro culture in media amended with different concentrations of different sucrose, fructose and glucose. (A) Difference of juice sac color by sucrose concentrations in the media (juice sacs inside photo were more elongated). (B) The difference of juice sac shape by sugar concentration in the media (juice sacs in sucrose media were larger and more elongated than those cultured in glucose and fructose, and $10 \%$ fructose were rounder). Juice sacs were more yellow at higher sugar concentration.

with $5 \%$ sucrose and lowest in media with the $20 \%$ fructose amendment. There were no significant differences in juice sac fresh weight for glucose at all concentrations, for fructose at 5 and $10 \%$, and for sucrose at 10 and $20 \%$ (Fig. 2). These results suggest that the juice sac growth in 'Shiranuhi' mandarin fruit is affected by sugar concentration and type, with sucrose being the most important sugar for juice sac enlargement.

The juice sac's shape was also affected by sugar concentration and type (Fig. 3). Juice sacs cultured in sucrose were more elongated, with explants in 5\% sucrose media showing more growth. Juice sacs in sucrose media were also generally larger and more elongated than those cultured in glucose and fructose. Juice sacs in $10 \%$ fructose were rounder than in the other treatments and similar in shape to satsuma mandarin juice sacs (data not shown) which means that the juice sac's shape in vitro may be determined by sugar concentration, type, and citrus variety. In terms of color, juice sacs were more yellow at higher sugar concentrations and the intensity of yellow coloration was observed to increase with sugar content (Fig. 3). This may be related to sugar accumulation processes and media conditions. Yakushiji et al. (1998) found that there is increased translocation of photosynthates into fruit juice sacs from trees under moderate drought stress, and that fructose and glucose accumulation in fruit is driven by active osmoregulation in satsuma mandarin. In this experiment, juice sac fresh weight and shape in vitro were shown to be highly responsive to sucrose concentration in media. However, the juice vesicles grew less with water potential decreased in media for satsuma mandarin fruit (Mukai et al., 2001). Thus, the shape, weight and color of juice sac may be affected by water potential and osmotic potential cultured in vitro in solid MS media increased with sugar concentration.

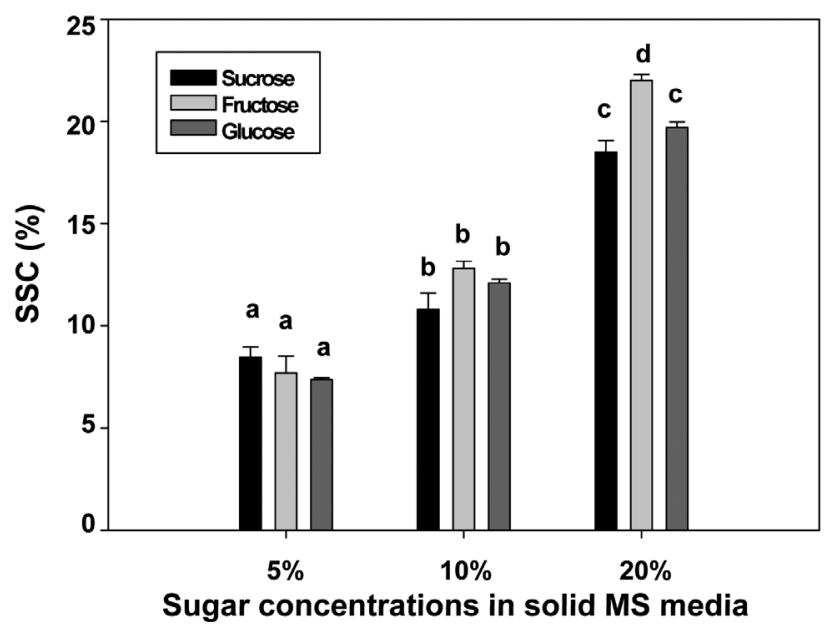

Fig. 4. Soluble solids content in 'Shiranuhi' $[(C$. unshiu $\times C$ sinensis) $\times C$. reticulate] mandarin juice sacs cultured in vitro in MS media supplemented with $1 \mathrm{mg} \cdot \mathrm{L}^{-1} \mathrm{BA}, 1 \%$ agar, and 5,10 , and $20 \%$ of sucrose, fructose and glucose, respectively. Bars are means \pm SE $(n=30)$ and columns with the same letter within treatment are not significantly different at $P=0.05$.

\section{SS Content and Acidity in Juice Sacs Exposed to Different Sugar Concentrations in Vitro}

Soluble solids in juice sacs that were cultured in vitro in solid MS media increased with sugar concentration and were highest in media with $20 \%$ sucrose, fructose and glucose (Fig. 4). There were no significant differences in the juice sac SS content at 5 and $10 \%$ sucrose, fructose and glucose; while it was significantly higher in fructose than in sucrose and glucose at $20 \%$ media amendment. Our results show that differences in fruit SS and quality in vitro as a function of sugar content in media is more pronounced in fructose than in sucrose and glucose. Similar result reported that SS content of juice vesicles were more accumulated with sucrose content in the medium (Mukai et al., 2001). Thus, differences 
in the juice sac SS may closely depend on sugar accumulation, sugar concentration, cell growth, and maturation.

Differences in the rate of maturation and sink strength capacity may also account for observed variations in fruit SS content as SS content has been reported to be closely linked to respiration activity (Bartholomew and Sinclair, 1941), maturation processes (Ting, 1969), osmotic potential (Yakushiji et al., 1996), differential sink strength at the enzyme level (Song et al., 1998), and differences in photosynthate accumulation (Kadoya, 1973; Moon and Mizutani, 2007).

Juice sac acid content at different sugar concentrations increased in the order of 20, 10, and 5\% sucrose, fructose and glucose in media (Fig. 5) with significantly higher acid content at 5 and $10 \%$ fructose. Acid content in juice sacs grown in media amended with different concentrations of sucrose, fructose and glucose was highest in the fructose treatment. 'Shiranuhi' mandarin fruit is oval in shape with higher sugar and acid content in the stylar end relative to other parts (Moon and Mizutani, 2002), and differences in the juice sac acidity in response to sugar concentration and type in vitro may be associated with sugar accumulation, cell growth, and stage of development as noted by Moon et al. (2009) for organic acid content within the different parts of juice sacs. The concentration of citric acid, the major organic acid in citrus, generally decreases with the fruit maturity but it has been found that acidity increases with water stress during fruit maturation (Moon and Mizutani, 2002; Moon et al., 2008). Thus, variations in the juice sac acid content in response to different sugar concentrations in vitro may be related to differences in osmotic pressure.

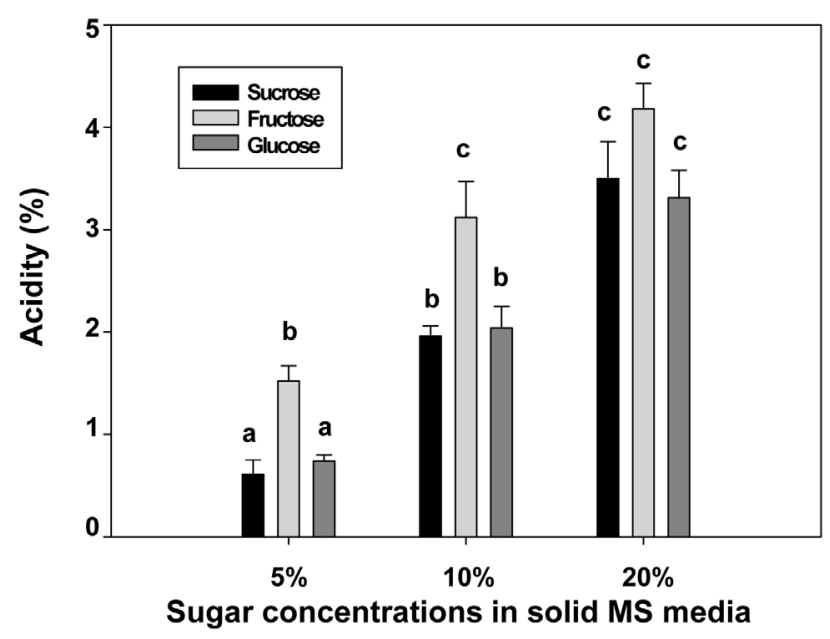

Fig. 5. Acid content in 'Shiranuhi' $[(C$. unshiu $\times$ C. sinensis $)$ $\times$ C. reticulate] mandarin juice sacs cultured in vitro in MS media supplemented with $1 \mathrm{mg} \cdot \mathrm{L}^{-1} \mathrm{BA}, 1 \%$ agar, and 5,10 , and $20 \%$ of sucrose, fructose and glucose, respectively. Bars are means \pm SE $(n=30)$ and columns with the same letter within treatment are not significantly different at $P=0.05$.
However, 'Shiranuhi' mandarin is known to generally have higher SS and acidity than satsuma mandarin.

Free Sugar Content in Juice Sacs Cultured in Vitro in Media Amended with Different Concentrations of Sucrose, Fructose, and Glucose

Sugar content (sucrose, fructose, and glucose) in juice sacs increased with sugar concentration in the media (Fig. 6). However, the juice sac fructose and glucose decreased with increasing sucrose content in the media. In the media amended with fructose, the juice sac fructose content was significantly higher at $20 \%$ with a similar observation made for the glucose treatment. The observation by Moon et al. (2009) that sucrose content increases from the central towards the outer parts while reducing sugars (fructose and glucose) increase inwards from outer parts in 'Shiranuhi' mandarin juice sacs suggests that there may be differences in how the various sugars impact juice sac growth. The higher fructose and glucose uptake at 5\% sucrose are similar to observations made by Huberman et al. (2005) for grapefruit whereby both hexoses (fructose and glucose) are uptaken during fruit growth and sucrose during fruit maturation. As indicated in Fig. 2 , the juice sac fresh weight was highest at 5\% sucrose. This may also explain why the juice sac fresh weight was highest at 5\% sucrose concentration (Fig. 2).

In the present study, sucrose, fructose and glucose content in juice sacs increased with increasing concentrations in media (Fig. 6) suggesting that sugar uptake by juice sacs is actively induced by increasing sugar concentrations in the media. Sucrose-metabolizing enzymes in sink tissues have an emphasized role in the capacity for sugar storage/utilization (Komatsu et al., 1999) and from our results we can conclude that sucrose is utilized more than fructose and glucose for juice sac growth.

However, sucrose and glucose contents slightly increased in the presence of fructose, and sucrose content was higher compared with glucose in the fructose treatment, and higher than fructose in the glucose treatment (Fig. 6). Hexose accumulation in mature fruit occurs via active osmoregulation (Yakushiji et al., 1996) and fruit load may greatly affect sucrose accumulation by controlling enzyme activity (Kubo, 2001). Thus, sucrose, fructose, and glucose uptake patterns in vitro may also be affected by osmoregulation and physiological moisture stress.

Sugar is transported to juice sacs through the phloem in the form of sucrose in citrus (Kubo et al., 2001; Lowell et al., 1989; Tomlinson et al., 1991). In our study, sugar in juice sac was accumulated with free sugar increased in the media. The variation in sugar content at different sugar concentration in MS media was probably due to differences 

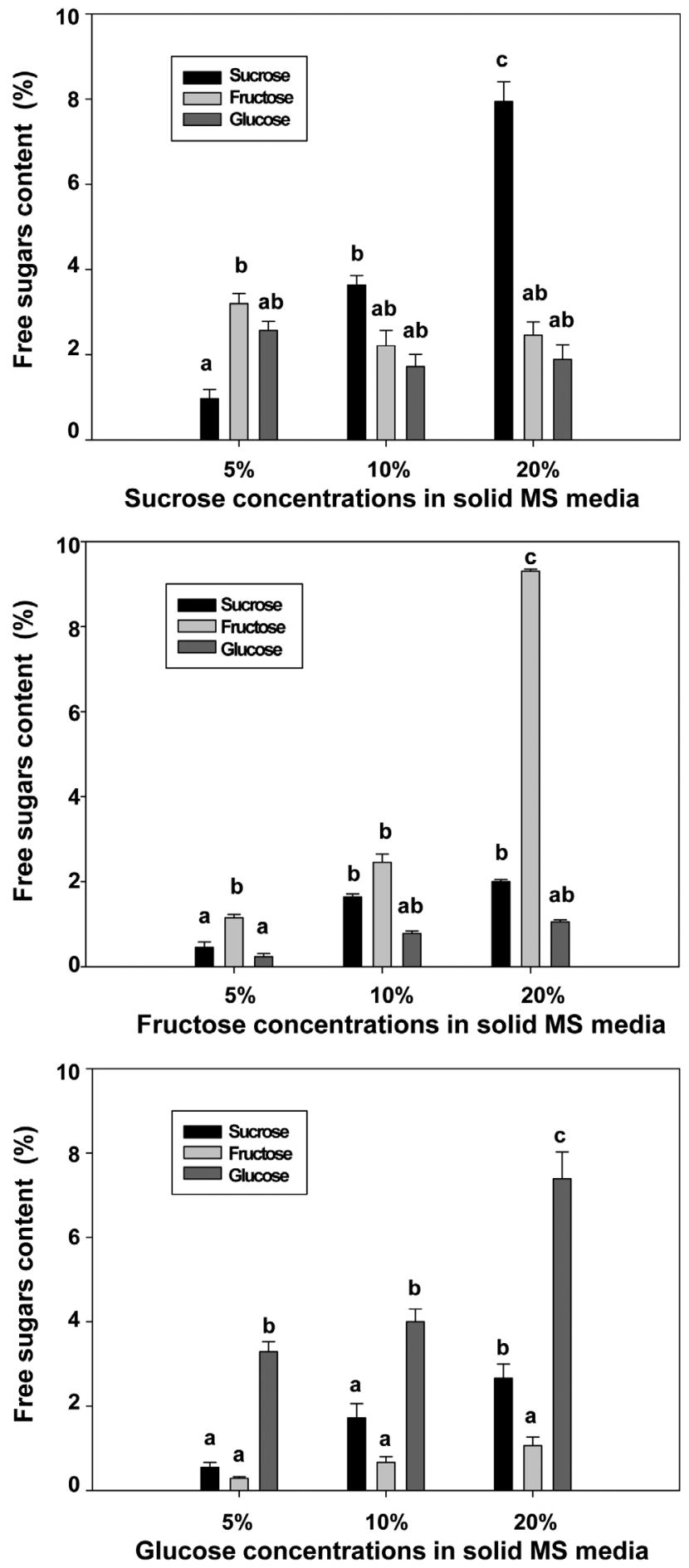

Fig. 6. Free sugar content in 'Shiranuhi' [(C. unshiu $\times$ C. sinensis $)$ $\times$ C. reticulate] mandarin juice sacs cultured in vitro in MS media supplemented with $1 \mathrm{mg} \cdot \mathrm{L}^{-1} \mathrm{BA}, 1 \%$ agar, and 5,10 , and $20 \%$ of sucrose, fructose and glucose, respectively. Bars are means \pm SE $(n=30)$ and columns with the same letter within treatment are not significantly different at $P=0.05$.

in maturation processes and metabolizing enzymes. Our results indicate that the juice sac was activated at $20 \%$ sugar concentration with yellow coloration being most intense (Fig 3). Lowell et al. (1989) reported that sucrose-metabolizing enzymes in transport tissues can be assimilated in juice sacs. The mechanisms of sugar transport into storage cells are major factors determining commercial fruit quality. Therefore, it would be interesting to study gene expression for maturation and color of juice sacs as affected by sugar deposition processes during growth and maturation of citrus fruit.

\section{Literature Cited}

Bartholomew, E.T. and W.B. Sinclair. 1941. Unequal distribution of soluble solids in the pulp of citrus fruits. Plant Physiol. 16:293-312.

Burns, J.K., D.S. Achor, and E. Echeverria. 1992. Ultrastructural studies on the ontogeny of grapefruit juice vesicles (Citrus paradisi Macf. cv. Star Ruby). Int. J. Plant Sci. 153:14-25.

Huberman, M., U. Zehavi, W.D. Stein, E. Etxeberria, and R. Goren. 2005. In vitro sugar uptake by grapefruit (Citrus paradise) juice-sac cells. Fun. Plant Biol. 32:357-366.

Kadoya, K. 1973. Studies on the translocation of photosynthates in satsuma mandarin. IV. Diurnal fluctuations of fruit growth and some environmental conditions. J. Jpn. Soc. Hort. Sci. 42:215-220.

Komatsu, A., Y. Takanokura, T. Moriguchi, M. Omura, and T. Akihama. 1999. Differential expression of three sucrose-phosphate synthase isoforms during sucrose accumulation in citrus fruit (Citrus unshiu Marc.). Plant Sci. 140:169-178.

Kubo, T., I. Hohjo, and S. Hiratsuka. 2001. Sucrose accumulation and its related enzyme activities in the juice sacs of satsuma mandarin fruit from trees with different crop loads. Sci. Hort. 91:215-225.

Lowell, C.A., P.T. Tomlinson, and K.E. Koch. 1989. Sucrosemetabolizing enzymes in transport tissues and adjacent sink structures in developing citrus fruit. Plant Physiol. 90:1394-1402.

Matsumoto, R. 2001. 'Shiranuhi' a late-maturing citrus cultivar. Bull. Natl. Inst. Fruit Tree Sci. 35:115-120.

Moon, D.G. and F. Mizutani. 2002. Relationship between fruit shape and acid content in different parts of citrus fruits. J. Jpn. Soc. Hort. Sci. 71:56-58.

Moon, D.G. and F. Mizutani. 2007. Partitioning of ${ }^{13} \mathrm{C}$-assimilates in different portions of maturing satsuma mandarin fruit. Hort. Environ. Biotechnol. 48:32-35.

Moon, D.G., S.W. Ko, K.C. Seong, and H.N. Hyun. 2009. Sugars and organic acid contents in different parts of juice sacs in 'Shiranuhi' mandarin fruit at harvest. J. Kor. Soc. Hort. Sci. 50:515-518.

Moon, D.G., S.W. Ko, S.G. Han, Y.H. Choi, and Y.H. Kim. 2008. Sugar and acid contents in different portions of 'Shiranuhi' mandarin fruit as affected by water stress. J. Kor. Soc. Hort. Sci. 49:216-220.

Mukai, H., T. Takagi, M. Iwatani, and H. Harada. 2001. Effects of sugar concentration and water potential in the medium on sugar accumulation by in vitro cultured juice vesicles of satsuma mandarin. J. Japan. Soc. Hort. Sci. 70:238-243 (In Japanese).

Mukai, H., T. Takagi, N. Kajita, S. Nishikawa, H. Harada, and Y. Murai. 2000. Sugar accumulation in fruit of several satsuma 
mandarin cultivars. J. Japan. Soc. Hort. Sci. 69:624-628 (In Japanese).

Murashige, T. and F. Skoog. 1962. A revised medium for rapid growth and bioassay with tobacco tissue cultures. Physiol. Plant 15:473-497.

Nii, N. and B.G. Coombe. 1988. Anatomical aspects of juice sacs of satsuma mandarin in relation to translocation. J. Japan. Soc. Hort. Sci. 56:375-381.

Saunt, J. 2000. Citrus varieties of the world. Sinclair Intl. Ltd., Norwich, UK. p. 15-156.

Song, K.J., E. Echeverria, and H.S. Lee. 1998. Distribution of sugars and related enzyme in the stem and blossom halves of 'Valencia' oranges. J. Amer. Soc. Hort. Sci. 123:416-420.

Spiegel-Roy, P. and E.E. Goldschmidt. 1996. Biology of citrus. p. 88-125. Cambridge University Press, Cambridge.

Ting, S.V. 1969. Distribution of soluble components and quality factors in the edible portion of citrus fruits. J. Amer. Soc. Hort. Sci. 94: 515-519.

Tomlinson, P., E.R. Duke, K.D. Nolte, and K.E. Koch. 1991. Sucrose synthase and invertase in isolated vascular bundles. Plant Physiol. 97:1249-1252.

Yakushiji, H., H. Nonami, T. Fukuyama, S. Ono, N. Takagi, and Y. Hashimoto. 1996. Sugar accumulation enhanced by osmoregulation in satsuma mandarin fruit. J. Amer. Soc. Hort. Sci. 121:466-472.

Yakushiji, H., K. Morinaga, and H. Nonami. 1998. Sugar accumulation and partitioning in satsuma mandarin tree tissues and fruit in response to drought stress. J. Amer. Soc. Hort. Sci. 123: 719-726. 